\title{
A regulamentação dos agrotóxicos no Brasil: entre o poder de mercado e a defesa da saúde e do meio ambiente
}

\author{
Victor Pelaez ${ }^{1}$ \\ Fábio Henrique Bittes Terra ${ }^{2}$ \\ Letícia Rodrigues da Silva ${ }^{3}$
}

\begin{abstract}
Resumo: Este trabalho traça um histórico da Lei 7802/89 que introduziu critérios - ambientais, de saúde pública e de desempenho agronômico - mais rígidos para os registros de agrotóxicos. Grupos de interesse sustentam que a maior exigência dos critérios de registro favorece uma estrutura oligopolizada controlada por empresas transnacionais, dificultando o acesso dos fabricantes de produtos equivalentes capazes de reduzir os preços. A hipótese deste artigo é de que esse argumento não tem fundamento empírico pois a indústria de agrotóxicos apresenta estrutura altamente concentrada em função das elevadas economias de escala e escopo, fazendo com que os efeitos de uma regulamentação mais rigorosa sejam marginais ou nulos. Para sustentar esta hipótese o artigo apresenta a evolução da estrutura de mercado de agrotóxicos no Brasil e, na sequência, resgata a trajetória do marco regulatório dos agrotóxicos sob uma abordagem institucionalista que trata da influência dos grupos de interesse sobre as instâncias de decisão do Estado.
\end{abstract}

Palavras-Chave: agrotóxicos; regulamentação; oligopólio; indústria; história.

\section{Agrochemical regulation in Brazil: market power vs. health and environment defense}

\begin{abstract}
This article aims to provide an historical retrospect of the Law 7802/89, which introduced stricter environmental, public health and agronomical performance criteria for registering agrochemicals. Groups of interest argue that stricter criteria for registering those products favor the maintenance of an oligopolistic structure controlled by transnational companies, which avoids the access to equivalent product companies able to reduce agrochemicals' prices. The hypothesis of this article states that this argument has no empirical foundation once this industry presents a highly concentrated structure due to high economies of scale and scope which makes the effects of a more stringent regulation marginal or ineffective. This hypothesis is sustained through the characterization of the Brazilian agrochemical

\footnotetext{
${ }^{1}$ Professor Adjunto do Departamento de Economia da UFPR. E-mail: victor@ufpr.br

${ }^{2}$ Professor Assistente do Instituto de Economia da UFU. Doutorando em Economia do PPGE/UFRGS. E-mail: fhbterra@yahoo.com.br

${ }^{3}$ Gerente de Normatização de Agrotóxicos da Anvisa. E-mail: letícia.silva@anvisa.gov.br
} 
market structure, followed by the description of the agrochemical regulatory body trajectory. Such a description is based on an institutionalist approach, which highlights the influence of interest groups over decision-making process of the state.

Keywords: pesticides; regulation; oligopoly; industry; history.

JEL: L22

\section{Introdução}

A evolução da indústria de agrotóxicos está diretamente ligada ao processo de modernização da agricultura no pós II Guerra, baseado no uso intensivo de insumos químicos, biológicos e mecânicos. No Brasil, este processo consolidou-se ao longo dos anos 1970, concomitantemente à constituição de um parque industrial de insumos para a agricultura, resultante da política de substituição de importações. No caso da indústria de agrotóxicos, foi de fundamental importância a criação em 1975 do Programa Nacional de Defensivos Agrícolas, no âmbito do II Plano Nacional de Desenvolvimento, que proporcionou recursos financeiros para a criação de empresas nacionais e a instalação de subsidiárias de empresas transnacionais no país. Outro fator importante foi a oferta de crédito de custeio, necessário à criação de uma demanda em larga escala de insumos para a agricultura, viabilizado pela criação do Sistema Nacional de Crédito Rural em 1965. Além disso, a existência de um marco regulatório defasado e pouco rigoroso, baseado no Regulamento de Defesa Sanitária Vegetal de 1934, que sofreu alterações significativas em 1978, mas permaneceu em vigor até 1989, facilitou o rápido registro de substâncias agrotóxicas, muitas delas já banidas pelas legislações de países desenvolvidos.

Os anos 1980 e 1990 foram marcados pela crise macroeconômica do país na qual a política de substituição de importações e o crédito agrícola abundante deram lugar a uma política recessiva voltada ao controle dos gastos públicos. Apesar da forte redução do crédito rural subsidiado pelo governo, o desempenho da agricultura nesse período foi significativo, contribuindo para o superávit da balança comercial, com um aumento de mais de 200\% do valor exportado. Somente na década de 1990 a produtividade média nacional de grãos teve um incremento de $44 \%$ e a produção um incremento de $54 \%$ (Coelho 2001). Este bom desempenho da agricultura nacional tem marcado também os anos 2000, com uma expansão no período 2000-2007 de 4,15\% contra uma taxa média de crescimento do PIB de 3,06\% (Ipeadata 2008). Nesse contexto produtivo o Brasil caracteriza-se como um grande mercado consumidor de agrotóxicos, sendo que em 2004 foi responsável por 13,5\% do faturamento da indústria mundial, terceiro maior índice em nível global, atrás apenas dos Estados Unidos e do Japão. Durante todo o período 1975/2007 o país sempre esteve entre os seis maiores mercados de agrotóxicos do mundo (Terra 2008). 
Em 1989 entrou em vigor uma nova lei regulamentando a fabricação e o uso dos agrotóxicos no país, em substituição ao antigo regulamento de 1934, tornando o processo de registro de agrotóxicos muito mais exigente. E face à retração das políticas públicas de incentivo à agricultura, determinados segmentos agrícolas têm se empenhado em alterar a legislação de agrotóxicos para facilitar o registro dos produtos-sobretudo dos equivalentes cujas patentes já expiraram-sob o argumento de que haveria uma significativa redução dos preços dos agrotóxicos e, consequentemente, sobre os custos de produção agrícola. A introdução do sistema de registro por equivalência tornou-se assim um importante foco de controvérsias entre as associações de grandes produtores rurais, das empresas fabricantes e dos órgãos reguladores. De um lado a Confederação Nacional da Agricultura (CNA) e a Associação Nacional dos Defensivos Genéricos (Aenda) alegam que o marco regulatório vigente favorece as grandes empresas transnacionais, cuja capacidade de investimento em $\mathrm{P} \& \mathrm{D}$ permite atender com mais facilidade as exigências dos órgãos de registro e fiscalização, o que contribuiria a uma concentração maior do mercado. De outro lado, os órgãos reguladores, particularmente a Agência de Vigilância Sanitária e o Ibama, consideram as exigências legais como condição fundamental para minimizar os riscos e perigos ao meio ambiente e à saúde do consumidor e dos trabalhadores rurais.

Nesse contexto, o objetivo deste trabalho é resgatar elementos de análise que contribuam para um debate controvertido, envolvendo o confronto de interesses públicos e privados, no qual é necessário saber até que ponto o marco regulatório, relativo ao registro dos agrotóxicos, pode afetar as características estruturais de um mercado altamente concentrado, tanto em nível nacional quanto internacional. Esta discussão pretende assim revelar uma estratégia de determinados grupos, do setor agrícola e agroindustrial, de buscar a legitimação de seus interesses de expansão no mercado nacional em argumentos exclusivamente econômico-conjunturais de curto prazo, mascarando uma problemática mais ampla sobre os impactos ambientais do uso continuado de agrotóxicos em larga escala.

Para atingir os objetivos propostos este artigo combina dois referenciais de análise: o de organização industrial, no sentido de identificar as principais características estruturais do mercado de agrotóxicos; e uma abordagem institucionalista baseada no nexo econômico-jurídico por meio do qual se estabelece o controle social do mercado, formando um espaço de ação dos interesses organizados nos processos de decisão do Estado (neocorporatismo).

Na seção 2 identificam-se as características estruturais do mercado de agrotóxicos no Brasil e sua evolução desde os anos 1980, de forma a indicar, os principais segmentos do mercado, as principais barreiras à entrada, as estratégias de concorrência, o grau de concentração e o poder de oligopólio das principais empresas do ramo. A indústria de agrotóxicos é um ramo pouco estudado no qual carecem bases de dados sistematizadas, fazendo com que as 
fontes de informação restrinjam-se a estudos empíricos escassos realizados nas últimas décadas. Procurou-se neste trabalho sistematizar essas informações e complementá-las com informações disponibilizadas pelas associações de classe e pelos relatórios anuais das grandes empresas líderes de mercado, em nível nacional e internacional. A seção 3 apresenta um histórico da evolução da regulamentação dos agrotóxicos a partir da Lei 7.802/89, procurando mostrar a influência e as pressões do setor privado sobre os órgãos públicos de registro e fiscalização, no sentido de flexibilizar as exigências estabelecidas na referida lei. As informações apresentadas nesta seção basearam-se nas leis e decretos específicos, disponíveis nos sítios do Poder Legislativo, em documentos oficiais do Poder Executivo, em declarações à imprensa dos principais atores envolvidos no debate sobre a regulamentação dos agrotóxicos, e em editoriais das associações de classe.

\section{A estrutura do mercado de agrotóxicos}

De acordo com a Lei 7.802/89 os agrotóxicos são definidos como: “os produtos e os agentes de processos físicos, químicos ou biológicos, destinados ao uso nos setores de produção, no armazenamento e beneficiamento de produtos agrícolas, nas pastagens, na proteção de florestas, nativas ou implantadas, e de outros ecossistemas e também de ambientes urbanos, hídricos e industriais, cuja finalidade seja alterar a composição da flora ou da fauna, a fim de preservá-las da ação danosa de seres vivos considerados nocivos." (Art. 2; § 1, item a). A ação esperada do agrotóxico ocorre pela presença em sua composição de um ingrediente ativo que incide sobre a atividade biológica normal dos seres vivos sensíveis a ele. A produção comercial de um agrotóxico envolve a obtenção do ingrediente ativo, cujo processo de síntese adotado irá determinar seu grau de pureza bem como o teor de impurezas. Esse composto obtido é chamado de produto técnico, que será utilizado para a formulação do produto final. A este são adicionados outros elementos químicos que garantem sobretudo a dispersão e a fixação do produto nas plantas a serem protegidas ou destruídas pelo efeito tóxico específico. O produto final, obtido da mistura do produto técnico com outros produtos químicos auxiliares, corresponde ao chamado produto formulado, que é aplicado nas lavouras.

A classificação dos agrotóxicos, por finalidade de uso, é definida pelo poder de ação do ingrediente ativo sobre organismos-alvo, como: inseticidas, fungicidas, herbicidas, nematicidas, acaricidas, rodenticidas, moluscidas, formicidas, reguladores e inibidores de crescimento. Dentre essas classes, as três principais, que representam cerca de 95\% do consumo mundial de agrotóxicos, são os herbicidas (48\%) inseticidas (25\%) e fungicidas (22\%) (Agrow 2007).

Os agrotóxicos podem também ser classificados em dois tipos, em função do 
regime de propriedade intelectual vigente: as novas moléculas, ou princípios ativos, passíveis de serem patenteadas garantindo o direito de exclusividade de comercialização às firmas inovadoras, bem como as parcelas mais lucrativas do mercado; e os produtos equivalentes ${ }^{4}$, cujas patentes já expiraram tornando a tecnologia de produção passível de ser explorada por empresas que não possuem capacidade de investimento em P\&D.

Já as empresas fabricantes de agrotóxicos podem ser classificadas em dois tipos: integradas e especializadas. As empresas integradas são subsidiárias dos grandes grupos da indústria química que apresentam um grande dinamismo tecnológico, posicionando-se como líderes nos respectivos segmentos de mercado em que atuam. O termo "integradas" refere-se ao fato de atuarem em todas as etapas da produção de agrotóxicos: da pesquisa e desenvolvimento de novas moléculas químicas, à distribuição e comercialização de produtos (técnicos e formulados). As empresas especializadas concentram-se, por sua vez, na fabricação de produtos técnicos cuja validade das patentes tenha vencido (produtos equivalentes) e também de produtos formulados (Frenkel \& Silveira 1996:43). Cabe ressaltar que no segmento do mercado de produtos equivalentes as empresas especializadas concorrem diretamente com as integradas que também atuam na comercialização de seus produtos formulados cuja patente tenha expirado. A estimativa da Aenda (2008) é de que as empresa especializadas detenham apenas de 15 a 20\% do mercado mundial de produtos equivalentes. Nesse contexto, a hegemonia das empresas integradas se exerce também pelo fato de serem, na maioria das vezes, as fornecedoras dos produtos técnicos às empresas especializadas na fabricação dos produtos formulados.

A caracterização de uma estrutura de mercado pode ser considerada a partir de três elementos fundamentais: o grau de concentração do mercado, em termos do market-share das vendas e do faturamento, as barreiras à entrada que constroem impedimentos à entrada de novos competidores, potenciais ou já atuantes no mercado e as formas de concorrência, sejam por preço e/ ou qualidade dos produtos e serviços (Possas 1985).

O mercado da indústria de agrotóxicos como um todo apresenta-se altamente concentrado em nível mundial. Em 2004 cerca de 10 empresas controlavam cerca de 98\% das vendas nas diferentes regiões do planeta (Defesa Agrícola 2006a: 2,3). Em 2007, as seis maiores empresas do ramo (Bayer, Syngenta, Basf, Monsanto, Dow, DuPont) controlavam 86\% do mercado mundial estimado em US\$ 33,4 bilhões (McDougall 2008). No Brasil a participação das onze maiores empresas do ramo foi estimada em 85\% do mercado em 2006

${ }^{4}$ Convencionalmente, usa-se na literatura sobre agrotóxicos o termo Agrotóxico Genérico (Silveira 1993; Martinelli \& Waquil 2002; Martinelli 2003). Todavia essa nomenclatura é inadequada, visto que o termo genérico refere-se a medicamentos, de modo que se adota neste trabalho o termo agrotóxicos equivalentes, conforme expresso pelo decreto n. 4.074 de 2002. Outras nomenclaturas utilizadas, sem perda de validade analítica são: agrotóxicos com patentes vencidas, com patentes expiradas, sem proteção de patentes, não protegidos por patentes. 
(Brasil 2007a).

As barreiras à entrada no ramo de agrotóxicos atuam de forma diferenciada em função da capacidade tecnológica e de investimento dos novos entrantes. Para as grandes empresas, já atuantes no ramo químico, as barreiras à entrada derivam principalmente do sistema de patenteamento e do ritmo de inovação tecnológica. O sistema de patenteamento, ao garantir legalmente a exclusividade de produção e comercialização a uma empresa, estabelece reservas de mercado à detentora do direito de propriedade. Essas empresas aproveitam a exclusividade no fornecimento dos produtos para adotarem estratégias de fidelização do consumidor para com sua marca comercial. Além disso, o patenteamento, ao permitir lucros extraordinários, oferece à empresa a possibilidade de re-inversão desses ganhos superiores em atividades de pesquisa e desenvolvimento. A acumulação de competências tecnológicas daí advindas faz com que a empresa possa desenvolver novos produtos a um ritmo superior à capacidade de novos entrantes, estabelecendo assim barreiras à entrada (Naidin 1985). A título de exemplo, em 2007 as três maiores empresas de agrotóxicos (Syngenta, Basf \& Bayer) investiram em média 489 milhões de dólares, o que corresponde em média a cerca de 7,5\% do seu faturamento (Syngenta 2007; Basf 2007; Bayer 2007). Segundo informações da Bayer, os custos para se desenvolver um novo ingrediente ativo teriam aumentado cerca de 4 vezes em 15 anos, passando de 60 milhões de dólares em 1990 para cerca de 250 milhões em 2005 (Short 2005).

Já para as empresas especializadas as barreiras à entrada no mercado de agrotóxicos são mais numerosas. Um primeiro fator é o acesso dificultado dessas empresas às matérias-primas que elas utilizam em seu processo produtivo. As empresas integradas tendem a controlar o fornecimento de matérias-primas para a produção de agrotóxicos, o que limita as possibilidades de acesso às fontes de insumos industriais e às possibilidades de diversificação de suas atividades nesse mercado (Frenkel \& Silveira 1996).

Um segundo fator que implica em barreiras à entrada no mercado é a capacidade financeira limitada das empresas especializadas, que são em sua maioria, de pequeno e médio porte. A escassa disponibilidade de recursos impede que essas empresas invistam elevados montantes em atividades de pesquisa e desenvolvimento, afastando-as de competir pelas parcelas mais lucrativas do mercado, as dos produtos patenteados. Por sua estrutura financeira não permitir manter investimentos em inovação de produtos, as possibilidades de explorar economias de escopo via diferenciação são mais limitadas, o que as torna mais suscetíveis às oscilações na demanda por agrotóxicos, resultantes da imprevisibilidade natural do desempenho das safras e da oscilação do próprio mercado de commodities agrícolas (Martinelli 2003). 
Um terceiro tipo de barreira à entrada às empresas especializadas deriva das dificuldades de distribuição e promoção dos produtos no mercado ${ }^{5}$. Por operarem com um portfólio menor de produtos, os custos para a distribuição dos mesmos é maior. Ademais, por não trabalharem via de regra com produtos patenteados, essas empresas possuem maiores dificuldades em criar a fidelidade do consumidor às suas marcas comerciais (Velasco \& Capanema 2006).

Um quarto tipo de barreira às empresas especializadas, principalmente as de menor porte, diz respeito ao financiamento ao produtor rural da compra de agrotóxicos oferecido pelas grandes empresas do ramo, como estratégia de substituição do crédito agrícola concedido pelo governo ${ }^{6}$ (Defesa Agrícola 2006b). A existência desse tipo de barreira pode ser ilustrada na declaração conjunta das três associações de classe da indústria de agrotóxicos:

\begin{abstract}
A falta de recursos do Governo limitou, em 2004, a apenas 12,5\%, as vendas de produtos fitossanitários com recursos do Crédito Rural. Assim, a grande maioria das vendas é financiada com recursos próprios da indústria, com prazos longos de em média 250 dias, o chamado Prazo Safra, impactando diretamente o fluxo de caixa e o risco assumido pelas empresas. Em 2004, a indústria financiou $60 \%$ de suas vendas com este prazo médio assumindo o risco cambial além de dar o aval para a operação financeira. Esse financiamento é ímpar no mundo. Os outros países praticam vendas à vista ou com financiamentos de curto prazo (Andef 2005).
\end{abstract}

Em 2006, o financiamento das vendas de agrotóxicos pela indústria teria chegado a 90\% do total, um valor equivalente a $\mathrm{R} \$ 7,6$ bilhões (Sindag 2007). Esta parcela da produção corresponde praticamente à parcela do mercado controlado pelas grandes empresas de agrotóxicos no país.

Um quinto tipo de barreira à entrada está ligado a fatores jurídicos e políticoinstitucionais de um mercado sujeito à regulamentação como o de agrotóxicos (Possas 2006). As atividades de regulamentação pública, especialmente no que tange aos critérios para a obtenção de registros para a comercialização de agrotóxicos, podem gerar barreiras à entrada, sobretudo às empresas especializadas de menor porte. Em 1998, a Aenda estimava que os custos para se obter o registro de um produto equivalente (formulado e seu respectivo produto técnico) estariam entre $\mathrm{R} \$ 300$ mil e $\mathrm{R} \$ 650$ mil (Aenda 1998). Além disso, o controle de qualidade toxicológica dos agrotóxicos está diretamente ligado à capacidade de investimento em tecnologias de produção. Vale ressaltar que as fábricas modernas dispõem de mecanismos para controlar as impurezas

\footnotetext{
${ }^{5}$ Encontram-se dentre as estratégias de promoção e distribuição de produtos atividades como: formas de comercialização, assistência técnica e suporte ao usuário, financiamento aos usuários, relação com usuários, linhas de produtos (Possas 2006).

${ }^{6}$ Sobre a política de crédito rural como incentivo ao desenvolvimento do mercado de agrotóxicos no Brasil, ver Terra (2008).
} 
resultantes dos processos de síntese de seus produtos agrotóxicos. No entanto, fábricas com tecnologia obsoleta, que possuem um menor controle sobre o processo de produção, podem gerar produtos com o mesmo ingrediente ativo, mas centenas ou milhares de vezes mais tóxicos que o produto de referência, devido à presença de impurezas de fabricação (Silva 2000:7).

No entanto, independente de uma regulamentação mais exigente, a possibilidade de se colocar no mercado um produto com qualidade inferior, tanto do ponto de vista toxicológico quanto de desempenho agronômico, pode gerar custos adicionais, derivados de efeitos adversos à saúde, ao meio ambiente e à produtividade das culturas. Tais custos seriam resultantes tanto de ações penais de responsabilidade quanto de perda de credibilidade das empresas no mercado, reduzindo a sua competitividade.

Para as empresas integradas a principal forma de concorrência é a diferenciação de produtos. Essa forma de competição busca superar a rápida obsolescência dos agrotóxicos, a qual se apresenta como o principal problema a ser enfrentado pelas líderes (Naidin 1986:53). O rápido ciclo de vida desses produtos é determinado por dois fatores. O uso intensivo de agrotóxicos tende a gerar a resistência dos organismos-alvo dessas substâncias, reduzindo a sua eficácia ${ }^{7}$. Ao mesmo tempo, os efeitos adversos dos agrotóxicos sobre o meio ambiente e saúde humana têm-se tornado cada vez mais presentes nas agendas de políticas públicas dos órgãos reguladores, sobretudo nos países desenvolvidos. Ambos os fatores passaram a ser identificados após 1960, duas décadas após o início da utilização dos primeiros agrotóxicos organoclorados, ainda hoje utilizados em muitos países (Velasco \& Capanema 2006:77). Em face deste cenário, as empresas inovadoras buscam desenvolver novas moléculas, tanto com efeitos agrotóxicos específicos quanto de amplo espectro e que apresentem menores efeitos residuais (tempo de permanência no solo e efeitos sobre organismos não alvos) e baixa toxicidade. Já as empresas especializadas baseiam as suas estratégias de concorrência em preços, sendo a diferenciação de produtos uma estratégia mais limitada, o que não descarta estratégias de concorrência baseadas em serviços diferenciados de distribuição e de assistência técnica (Silveira 1993:8).

Considerando-se a evolução do grau de concentração do mercado Brasileiro de agrotóxicos de 1980 aos anos 2000, observa-se, pelo gráfico 1, uma tendência crescente de concentração do mercado. Nesse período, o market-share das duas maiores empresas elevou-se, em 21\%, passando de 27,5\% para 31,5\%; o das quatro maiores aumentou $27 \%$, passando de $41 \%$ para cerca de $53 \%$; e o das oito maiores subiu 24\%, passando de $62 \%$ para $77 \%$. A década intermediária de 1990, revela ligeira desconcentração no market-share das duas e das quatro maiores empresas, mas um aumento da concentração na participação de mercado das oito maiores, indicando uma tendência histórica de concentração inerente às características estruturais desse mercado.

${ }^{7}$ Para maiores informações sobre a resistência de pragas ver International Survey of Herbicide Weeds em_www. weedscience.org. 
GRÁFICO 1. EVOLUÇÃO DO GRAU DE CONCENTRAÇÃO DA INDÚSTRIA DE AGROTÓXICOS NO BRASIL, DÉCADAS DE 1980 A 2000

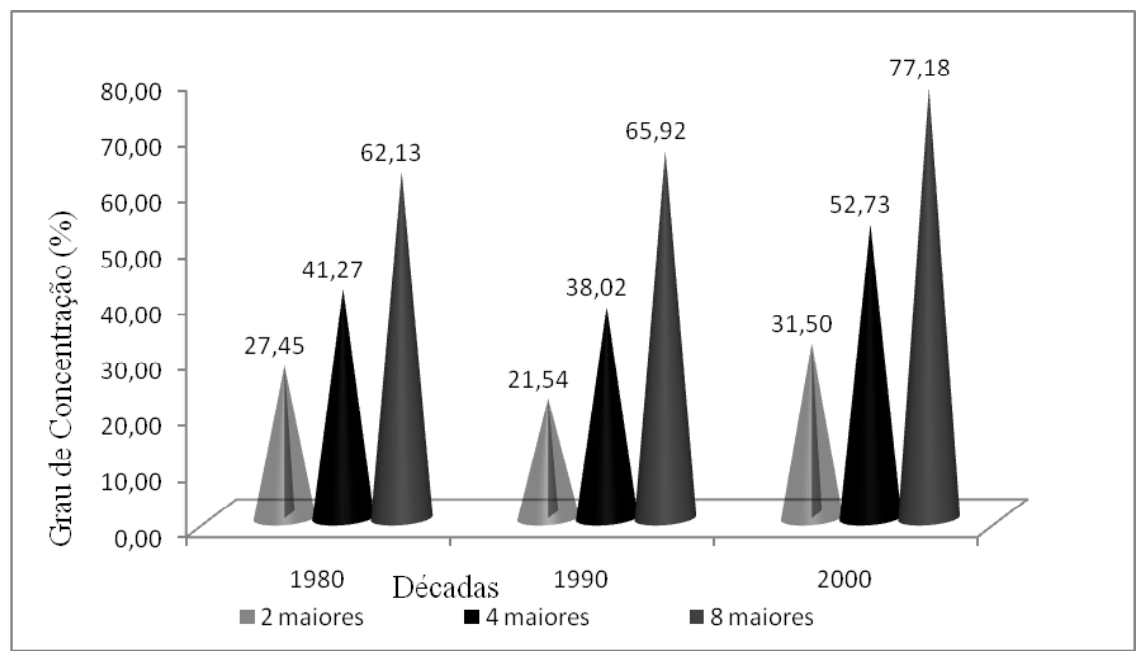

FONTE: Silveira (1993: 60); Martins (2000: 76); Brasil (2007a)

Nota - década de 1980, valor médio dos anos 1981, 1983, 1988; década de 1990, valor médio de 1990, 1995, 1998 e 1999; e década de 2000, valor médio de 2003, 2004, 2005 e 2006.

TABELA 1. PARTICIPAÇÃO RELATIVA NO MERCADO BRASILEIRO DE AGROTÓXICOS PATENTEADOS E COM PATENTE VENCIDA, 2006

\begin{tabular}{lrrrr}
\hline Produto & \multicolumn{3}{c}{ Quantidade (ton) } & \multicolumn{1}{c}{ Valor } \\
& Formulado & \multicolumn{1}{c}{ Técnico } & \multicolumn{1}{c}{ Total } & \multicolumn{1}{c}{ (US\$ 1000) } \\
Patenteado & $87.260(18 \%)$ & $28.144(12 \%)$ & $115.404(16 \%)$ & $1.795 .815(46 \%)$ \\
\hline Patente vencida & 392.860 & 210.572 & $603.432(84 \%)$ & $2.124 .026(54 \%)$ \\
& $(82 \%)$ & $(88 \%)$ & & \\
TOTAL & 480.120 & 238.716 & 718.836 & 3.919 .026 \\
& $(100 \%)$ & $(100 \%)$ & $(100 \%)$ & $(100 \%)$ \\
\hline
\end{tabular}

Fonte: Sindag (2008) 
Outro aspecto relevante, indicado na tabela 1 , diz respeito à participação relativa dos produtos patenteados e com patentes vencidas, comercializados no mercado nacional. A fabricação de produtos patenteados, em termos de quantidade é significativamente menor (16\%) do que a de produtos com patente vencida, que corresponde a $84 \%$ do volume produzido. Proporcionalmente porém o valor das vendas é significativamente alterado - 46\% para produtos patenteados contra 54\% para produtos com patente vencida - indicando o elevado valor agregado dos produtos patenteados em relação àqueles com patente vencida. Considerando-se como referência um grau de concentração de mercado entre 80\% e 90\% das 11 maiores empresas, como indicado na tabela 1, pode-se inferir que parcela significativa do lucro das grandes empresas (integradas e especializadas) é procedente da comercialização de agrotóxicos com patentes expiradas, uma vez que estes representam mais de 3/5 em quantidade e mais da metade em valor das vendas. Isto significa que os efeitos de um marco regulatório mais exigente sobre a estrutura de mercado dessa indústria, especialmente no que tange às barreiras à entrada às empresas de menor porte, podem ser marginais ou nulos.

\section{O marco regulatório dos agrotóxicos a partir da lei $7.802 / 89$}

Em 1989 foi aprovada no Congresso Nacional a Lei 7.802, conhecida como a Lei dos Agrotóxicos, que substituiu o Decreto 24.114 de 1934, posteriormente regulamentada pelo decreto n. 98.816 de 11 de janeiro de 1990 e substituído no ano de 2002, pelo Decreto 4074, de 04 de janeiro de 2002. O grande avanço dessa lei deu-se com o estabelecimento de regras mais rigorosas para a concessão de registro aos agrotóxicos. A nova legislação previu, desde a proibição do registro de novos agrotóxicos, caso a ação tóxica deste não fosse igual ou menor do que a de outros produtos já existentes destinados a um mesmo fim, até a possibilidade de impugnação ou cancelamento do registro por solicitação de entidades representativas da sociedade civil $^{8}$ (Brasil 1989: art. $5^{\circ}$ ).

Na busca por uma rastreabilidade maior das infrações causadas pelos agrotóxicos, todos os agentes diretamente envolvidos no manuseio de agrotóxicos, desde os produtores até os aplicadores dos produtos, deveriam cadastrar-se nos órgãos competentes (Idem: art. $4^{\circ}$ ). Foi instituída a obrigatoriedade do receituário agronômico para a venda de agrotóxicos (Idem: art. 13) e estabelecidas as normas e padrões das embalagens, assim como as normas, padrões, e instruções dos rótulos dos produtos (Brasil 1989: art. $7^{\circ}$ ). Modernizaram-se as responsabilidades administrativas por qualquer dano causado pelos agrotóxicos, e atualizaram-se os valores das infrações (Silva 2007).

${ }^{8} \mathrm{O}$ registro dos agrotóxicos poderia ser cancelado a partir de requisição de entidades de classe e representativas de atividades ligadas aos agrotóxicos, partidos políticos desde que representados no Congresso Nacional, e por entidades legalmente constituídas para a defesa dos interesses coletivos relacionados à proteção do consumidor, do meio ambiente e dos recursos naturais (Brasil 1989: art. $5^{\circ}$ ). 
A nova estrutura de registro dos agrotóxicos passou a ser compartilhada pelos Ministérios da Agricultura, da Saúde e do Meio Ambiente ${ }^{9}$. Ao Ministério da Agricultura coube a avaliação do desempenho agronômico do produto, ao da Saúde a avaliação toxicológica e ao do Meio Ambiente a avaliação ambiental. O decreto n. 98.816 normatizou os critérios a serem analisados pelos órgãos competentes, que publicaram posteriormente portarias com a normatização específica para as respectivas avaliações (Tomita 2005; Silva 2007).

De acordo com Kageyama (1990), apesar de a nova legislação introduzir regras rigorosas para pesquisa, produção, comercialização e uso dos agrotóxicos, os órgãos fiscalizadores do poder público não foram munidos com recursos materiais, humanos e financeiros necessários para as atividades de registro e fiscalização dos agrotóxicos. Com a dimensão territorial do país, pelas suas extensas fronteiras terrestres, e pelo rápido avanço da área e da produção agrícola, a prática fiscalizadora ficou muito aquém do necessário, se levada em conta a utilização intensiva de agrotóxicos na produção agrícola nacional.

Além disso, embora a lei apresentasse diversos avanços, entre os quais um maior rigor para a concessão dos registros, preocupando-se com os possíveis efeitos nocivos dos agrotóxicos sobre o meio ambiente e a saúde humana, ela deixou ainda pontos polêmicos no que concerne aos parâmetros de avaliação e à atribuição de fiscalização do poder público. Nos capítulos que tratam sobre as competências e sobre o registro dos agrotóxicos, o novo marco regulatório sedimentou nas mãos do Poder Executivo a prescrição dos parâmetros oficiais que deveriam ser cumpridos para as avaliações que concederiam o registro. Os parâmetros seriam criados a partir de decretos ministeriais. Esse formato de normatização das avaliações e posterior classificação dos agrotóxicos, por ser fruto de regulamentos ministeriais, não estiveram sujeitos à aprovação do Congresso Nacional. Assim sendo, tais parâmetros tornaram-se passíveis de serem alterados em função dos critérios definidos pelos administradores em exercício de diferentes governos (Bull \& Hathaway 1986).

Este espaço discricionário de exercício do Poder Executivo tornou-se o foco de ação dos grupos de interesse representados por associações de classe dos diferentes segmentos da indústria de agrotóxicos-como a Andef, Aenda e Sindag-e de parte do setor agrícola, por meio da Confederação Nacional da Agricultura (CNA). As estratégias de intervenção dessas associações junto às instâncias de decisão do governo federal configuram o que Belik (1992) denomina de mesocorporatismo. Nesse ambiente, as esferas econômica e política interagem, por meio de um jogo de forças buscando a legitimação e legalização de interesses privados. A interpenetração dessas esferas constitui, um nexo "econômico-jurídico" no qual, as empresas buscam, sobretudo estabelecer ex ante regras do jogo favoráveis a sua atuação no mercado (Samuels 1989). Desta

${ }_{9}^{A}$ À época da promulgação do decreto regulamentador, o Ministério do Meio Ambiente não existia, sendo responsável pelas avaliações ambientais a Secretaria do Meio Ambiente do Ministério do Interior (Tomita 2005). 
forma, a alocação eficiente de fatores não é determinada exclusivamente pelo mercado mas pela ação concomitante dos agentes que configuram as condições de concorrência. E a capacidade de influenciar as decisões de governo e de suas agências reguladoras envolve, ao nível das organizações privadas, a geração e a gestão de um conjunto de competências (gerenciais, técnicas e políticas) capazes de garantir tanto uma representação efetiva de seus interesses, quanto de implementar estratégias eficazes de intervenção nos processos de tomada de decisão do poder público (Terra \& Pelaez 2007).

\subsection{As modificações no registro de agrotóxicos}

As alterações no registro de agrotóxicos aconteceram, por meio de dois Decretos Presidenciais (4074/02 e 5801/06), após intensas pressões advindas das associações representativas dos interesses rurais Brasileiros e da associação de empresas especializadas na produção de agrotóxicos sem proteção de patentes (Aenda 1998; Brasil 2007b).

Os argumentos dos grupos de pressão voltados ao questionamento das exigências de registro de agrotóxicos, podem ser observados em declarações das associações de classe da indústria. Segundo a Associação Nacional das Empresas da Química Fina, Biotecnologia e suas Especialidades - Abifina (2005), a pesquisa e a experimentação de novos agrotóxicos passaram a ter parâmetros legais balizadores, o que significou maiores restrições à atuação das empresas em atividades de pesquisa e desenvolvimento. A Aenda (1998) argumentava que o novo marco regulatório representou um maior custo e um maior tempo de espera para a obtenção de novos registros, assim como maiores gastos com promoção de produtos, em função das novas exigências de embalagem, rotulagem e do receituário agronômico, o que exige maiores investimentos em equipes de venda e assistência técnica. Em declaração mais recente da Aenda (2001) isso teria contribuído à criação de barreiras à entrada no mercado para as empresas especializadas, que passaram a ter custos maiores para empreender todos os testes exigidos para a concessão dos registros, o que colaborou para a manutenção de um elevado grau de concentração do mercado.

Já os interesses dos agricultores manifestaram-se, entre outros, por meio de um de seus porta-vozes da bancada ruralista, a Senadora Kátia Abreu ${ }^{10}$ que, na $36^{\mathrm{a}}$ Reunião da Comissão de Assuntos Sociais do Congresso Nacional, realizada em setembro de 2007 , declarava:

${ }^{10}$ Pertencente, em 2007, ao Partido Democratas. 
Quero aqui também fazer justiça porque tudo isso é regulamentado por um decreto, um decreto absurdo que nós conseguimos, em outubro ou novembro, depois do segundo turno do ano passado, nós conseguimos negociar na Casa Civil e eu quero fazer justiça e louvar a Ministra Dilma Roussef que foi de muita coragem [...] que coordenou esse trabalho junto com a CNA, da qual faço parte, e conseguimos mudar este decreto (Brasil 2007b:2).

As insatisfações da Senadora não restringiram-se ao decreto regulamentador dos agrotóxicos, mas incluíram também quadros técnicos da Anvisa, os quais, na visão da senadora “[...] protegem a Andef. A Andef é a poderosa Associação Nacional das Multinacionais responsáveis por quatro bi e meio de comercialização anual neste país.” (Idem). O meio pelo qual os funcionários da Anvisa protegiam a Andef, segundo a Senadora, consistiu em “[...] essas três pessoas são, na realidade, [...], três figuras sinistras que há dez anos impedem os defensivos genéricos [equivalentes] de serem registrados no país." (Idem).

Meses depois, em dezembro de 2007, durante a reunião da Comissão de Assuntos Sociais no Senado que sabatinou o diretor da ANVISA (Dirceu Raposo de Melo) para seu segundo mandato, a Senadora Kátia Abreu declarou publicamente seu voto favorável à recondução ao cargo do Sr. Raposo de Melo em troca da promessa de agilização do processo de liberação de agrotóxicos equivalentes. Essa passagem foi publicada em 25 de dezembro no O Estado de São Paulo (2007):

Descontente com a lentidão da análise de processos para liberação dos agrotóxicos, a senadora Kátia Abreu (DEM-TO) avisou que iria pedir vista do processo - o que atrasaria a recondução de Raposo Melo. Fui chamada então para um café da manhã na casa de Chinaglia com a participação de Dirceu e do deputado Ronaldo Caiado, contou a senadora. De acordo com Kátia, ao chegar ao encontro Dirceu foi logo perguntando: O que posso fazer por você? Ela pediu rapidez. E ele concordou. A assessoria de imprensa da ANVISA confirmou o encontro. A conversa, que seria mantida em reserva, porém, foi revelada pela própria senadora, antes de ela declarar seu voto durante a sabatina. Depois da sessão no Senado ela contou: Queria o compromisso público. Deu resultado. Logo depois da Sessão, Melo ligou para o deputado Ronaldo Caiado combinando um novo encontro. As revelações feitas pela senadora durante a audiência provocaram constrangimento. Agências reguladoras foram criadas na tentativa justamente de manter independência. Seu regulamento foi feito principalmente pensando em blindar diretores contra eventuais pressões de setores produtivos ou políticos.

Com essa prática de influência política, além de pretender reduzir os custos de produção, segundo o discurso da Senadora Kátia Abreu, as mudanças na legislação provocariam no Brasil a redução no grau de concentração do mercado de agrotóxicos, visto que, as dificuldades para o registro de agrotóxicos, foram atribuídas a alguns funcionários da Anvisa e ao decreto n. 4.074/02, que regulamentou os agrotóxicos equivalentes. Ainda segundo as palavras da Senadora: 
É uma proteção e uma reserva de mercado absurda. Os produtos da China hoje são produtos de altíssima qualidade, embora muitos, que querem proteger as multinacionais que estão no país [Brasil], não queiram concordar com isso. Todos os produtos hoje, os defensivos na China e na Índia, todos são genéricos [equivalentes]. A grande maioria são genéricos [equivalentes], quase que 100\% são genéricos [equivalentes], e por que é que o Brasil ainda está na contramão da história, resistindo a isso? (Idem)

A CNA ${ }^{11}$, por sua vez, propunha em suas reivindicações que os agrotóxicos pudessem ser importados diretamente pelos agricultores do país, sem necessidade de registro prévio. E, uma segunda proposição, pretendeu concentrar apenas no Ministério da Agricultura todo o processo de registro, retirando as participações do Instituto Brasileiro do Meio Ambiente (Ibama) e da Anvisa, eliminando assim as competências de avaliação de risco ambiental e à saúde humana com vistas a reduzir a burocracia da divisão tripartite do registro (Brasil 2007b).

As ações da CNA têm contado com o apoio da Associação Nacional dos Defensivos Genéricos (Aenda), entidade que reúne pequenas empresas e importadores de agrotóxicos com patente expirada. Ambas instituições utilizam-se da bancada ruralista no Congresso Nacional para coordenar suas estratégias de pressão junto ao Poder Executivo e Legislativo. Segundo a Associação:

A luta da AENDA para flexibilizar as exigências para obtenção de registros dos defensivos agrícolas genéricos [agrotóxicos equivalentes], e conseqüentemente, aumentar a sua oferta e diminuir o preço ao produtor rural, é apoiada por deputados federais e senadores de vários partidos, conscientes da importância econômica e social da questão (Aenda 1998a:1).

Tal lobby visa sobretudo criar um sistema simplificado de registro que permitiria a essas empresas um acesso mais amplo, rápido e barato ao mercado nacional, vindo de encontro aos interesses de uma parcela significativa de produtores rurais interessados em terem seus custos de produção reduzidos. Já as organizações que representam as empresas líderes, Associação Nacional de Defesa Vegetal (Andef), Sindicato Nacional da Indústria de Produtos para Defensa Agrícola (Sindag) e a Abifina, posicionaram-se como favoráveis à simplificação do sistema de registro (em favor do registro por equivalência) desde que este guardasse todas as avaliações necessárias à proteção da saúde humana e do meio ambiente (Defesa Agrícola 2006c: 4).

${ }^{11} \mathrm{~A}$ CNA possui uma força de protesto considerável. Em 28 de junho de 2005, por exemplo, ela promoveu o movimento do "Tratoraço" no qual 12 mil pessoas ocuparam com veículos urbanos, máquinas, e implementos rurais a Esplanada dos Ministérios em Brasília, reivindicando a renegociação das dívidas dos produtores agropecuários e mais fontes oficiais de crédito para a atividade. Segundo a própria CNA (2007) o "Tratoraço" propunha-se a ser a maior manifestação já vista no país. 
O apoio à manutenção de uma legislação mais rigorosa, provinha principalmente de diversas entidades representativas da sociedade civil ${ }^{12}$. Em um documento endereçado, em 2005, ao então Ministro da Agricultura, Roberto Rodrigues, as entidades construíram uma pauta de reivindicações:

Que sejam mantidas as normas que garantem o controle e a fiscalização dos agrotóxicos no país, impedindo-se toda e qualquer flexibilização dos critérios de importação e registro dos produtos; [...] que toda e qualquer modificação na legislação que regulamenta os agrotóxicos no Brasil tenha por base um amplo debate público e um processo transparente e democrático de consulta à sociedade civil. (Consea 2007)

Ao setor público, principalmente o Poder Executivo, na figura da Casa Civil, coube intermediar os conflitos de interesses no processo de simplificação do registro e o resguardo das proteções contra a toxicidade dos agrotóxicos para o ser humano e para o meio ambiente. Ocorreram várias reuniões na Casa Civil da Presidência da República, nas quais representantes dos diversos interesses participaram das discussões para alteração do marco regulatório ${ }^{13}$. Mas foram principalmente os representantes das empresas do ramo de agrotóxicos que tiveram uma ação mais incisiva e eficaz nessa disputa, como revela o editorial da Aenda (2005:1):

Foram quatro anos de namoro da AENDA com os altos escalões dos ministérios da Agricultura, da Saúde e do Meio Ambiente, mostrando que o aumento da oferta dependia da implantação do registro por similaridade [equivalência]. Relações inférteis. Finalmente a Casa Civil se apaixonou pela causa dos defensivos genéricos [equivalentes], na pessoa do Ministro Pedro Parente e do Chefe Executivo Silvano Gianni.

Os grupos de pressão, oriundos do setor agrícola e da indústria de agrotóxicos, lograram assim alterar o decreto n. 98.8116/90 que, segundo eles, atravancaria a expansão da oferta e a redução dos preços dos agrotóxicos, assim como impedia a desconcentração do mercado nacional. Neste cenário, ocorreram duas importantes modificações: o já mencionado decreto n. 4.074 de $2002 \mathrm{e}$ o decreto n. 5.981 de 2006.

\footnotetext{
${ }^{12}$ Central Única dos Trabalhadores (CUT), Comissão Pastoral da Terra, Greenpeace, Instituto Brasileiro de Defesa do Consumidor (IDEC), Instituto de Estudos Socioeconômicos (INESC), entre outras (CONSEA 2007).

${ }^{13}$ Órgãos governamentais, como Anvisa, Ibama, Ministérios da Agricultura, do Planejamento e a própria Casa Civil, Associações da indústria de agrotóxicos, tanto das empresas líderes como das empresas especializadas, representantes do setor agrícola, estiveram presentes nos diversos debates que se seguiram (Brasil 2007a; Andef 2003).
} 


\subsection{0 decreto n. 4.074/o2}

O decreto n. 4.074 começou a ser pensado antes das primeiras representações contrárias ao Brasil no Mercosul, devido aos atrasos que o país estava causando na harmonização dos registros necessários à livre circulação dos agrotóxicos no bloco. Criou-se em 2000 um grupo para elaborar um novo decreto regulamentador da Lei 7.802, em substituição ao de n. 98.816/90.

As duas principais requisições junto ao grupo vieram no sentido de agilizar, harmonizar e racionalizar o sistema de registro, e sugerir propostas quanto ao procedimento a ser adotado para o registro do então chamado agrotóxico similar (Brasil 2005).

Em 4 de janeiro de 2002, publicou-se o decreto n. 4.074, que introduziu uma série de modificações no sistema de registro objetivando adequar a legislação nacional ao Mercosul e trazer celeridade ao processo de obtenção de registro, com vistas a reduzir o longo tempo e os elevados custos para a concessão dos registros. A mais importante modificação foi o estabelecimento do registro para produtos técnicos equivalentes ${ }^{14}$ (Brasil 2002: art. 10). Esse registro processa-se por meio da comparação entre características físico-químicas de um produto já registrado com as do candidato à equivalência. A lógica por trás desse tipo de registro é a de que, com padrões físico-químicos equivalentes, o perfil dos efeitos toxicológicos também seria equivalente aos dos produtos já registrados, estabelecendo também parâmetros nos quais os produtos (pleiteante e de referência) podem diferir entre si.

Anteriormente ao decreto n. 4.074/02, as empresas interessadas em produzir agrotóxicos com patentes vencidas, registravam seus produtos por bibliografia. Isto é, elas recolhiam referências bibliográficas disponíveis na literatura internacional, sobre testes de toxicidade crônica dos produtos que pretendiam registrar. Por meio desse procedimento, não se fazia qualquer comparação entre a composição físico-química do produto pleiteante para registro e o produto já registrado, sendo que frequentemente as referências bibliográficas apresentadas indicavam diferentes parâmetros de análise fazendo com que os critérios de avaliação fossem muito mais subjetivos e com menor rigor. Desta forma, a pretendida flexibilização do registro de agrotóxicos visando a redução de barreiras regulatórias, da parte de segmentos da agricultura e da indústria de agrotóxicos com patente vencida, acabou gerando na prática um efeito contrário.

Os grupos de pressão continuaram assim atuando junto ao Poder Executivo, o que levou à edição de mais um decreto (5981/06), publicado em dezembro de 2006, com vistas à uma agilização maior do processo de registro dos agrotóxicos.

${ }^{14} \mathrm{O}$ primeiro organismo a reconhecer e regulamentar os procedimentos para reconhecimento de produtos equivalentes foi a FAO - Organização das Nações Unidas para Agricultura e Alimentação em 1999 (FAO 1999). 


\section{3 $O$ decreto n. 5.981/o6}

Devido à quantidade e diversidade de provas documentais necessárias ao atendimento da avaliação toxicológica, ecotoxicológica dos produtos candidatos a registro, o decreto n. 5.981 procurou simplificar o processo de avaliação por meio de três fases sucessivas em termos de grau de exigência. Na primeira, devem ser apresentados os laudos técnico-científicos dos processos físicoquímicos e dos processos de síntese. Caso o produto, candidato a equivalente, esteja dentro dos parâmetros de equivalência do produto de referência este será aprovado. Caso apresente desvio além do permitido, em relação aos laudos técnico-científicos do produto de referência, passa-se a uma segunda fase. Nesta, realizam-se as avaliações quanto à toxicidade aguda e mutagenicidade dos produtos técnicos candidatos. Se os resultados destes diferirem do produto de referência registrado, passa-se a uma terceira fase, na qual são realizados testes de toxicidade crônica. O produto técnico candidato a registro por equivalência, que conseguir enquadrar-se, em uma das três fases, nos intervalos de segurança aceitos, obtém o registro. Se, por ventura, o produto candidato a registro não conseguir comprovar a equivalência em nenhuma das três fases de testes, o produto pode candidatar-se ao registro de produto técnico tradicional, com a apresentação de todos os estudos (Brasil 2006: art. 10). Desta forma, o sistema de registro foi simplificado, ao separar o processo de avaliação em etapas sucessivas que evoluem em grau de complexidade, sem perder o rigor do processo de avaliação (Brasil 2007b).

Devido ao curto espaço de tempo de vigência do decreto n. 5.981/o6 e ao número de novos produtos registrados, ainda não é possível avaliar os impactos dos novos procedimentos de registro para produtos equivalentes no desempenho e na estrutura do mercado de agrotóxicos.

\section{Conclusão}

A evolução do marco regulatório dos agrotóxicos reflete o resultado das estratégias mesocorporativas de ação de segmentos da indústria de agrotóxicos e do setor agrícola, notadamente junto aos espaços de decisão e arbitragem do Poder Executivo, nas suas atribuições de regulamentar a Lei de Agrotóxicos e as ações das empresas, por meio das agências reguladoras. Concomitantemente, a evolução do marco regulatório reflete um conflito de interesses, não apenas entre agentes reguladores e empresas reguladas, mas também entre as próprias empresas, em função da sua capacidade de adaptação aos critérios mais rígidos de registro de substâncias tóxicas. Por um lado as grandes empresas, tanto as integradas quanto as especializadas, apresentam uma capacidade maior de investimento nos estudos agronômicos, toxicológicos e de impacto ambiental, necessários ao registro dessas substâncias. Isto tende a facilitar o acesso das mesmas em diferentes segmentos de mercado, acentu- 
ando a sua estratégia de diferenciação de produtos. Por outro lado, possíveis flexibilizações na lei, ou alterações que levem a um processo de registro mais ágil, beneficiam tanto as empresas de menor porte quanto as de grande porte que também atuam na venda de produtos com patentes vencidas. As grandes empresas, beneficiam-se ainda da possibilidade de aumentarem as vendas de seus produtos técnicos àquelas de menor porte, para a fabricação de produtos formulados. Desta forma, as evidências apresentadas com relação às características estruturais do mercado indicam que os efeitos de uma regulamentação mais rigorosa no registro dos agrotóxicos tendem a ser marginais sobre um oligopólio concentrado, caracterizado por elevadas economias de escala e de escopo-tanto na $\mathrm{P} \& \mathrm{D}$, quanto na produção e na comercialização dessas substâncias.

Assim, os argumentos utilizados pela Aenda e a CNA, em defesa do bem público, voltado à redução dos preços dos agrotóxicos, por meio de uma redução da concentração do mercado, ainda carece de fundamento empírico. É portanto necessário uma verificação ex post da evolução da concentração do mercado na indústria de agrotóxicos, bem como da evolução dos preços desses produtos, após um período de tempo de ação do Decreto 5981/o6. Deve-se ponderar, neste caso, que mesmo a existência de uma possível queda de preços, ou aumento da concorrência em determinados produtos, pode ter um efeito limitado ou pouco representativo vis-à-vis a dinâmica estrutural do mercado como um todo. Em outras palavras, mesmo que a flexibilização do marco regulatório permita reduzir os possíveis efeitos de barreira à entrada a empresas de menor porte, outras características estruturais, mais numerosas e relevantes (controle das matérias-primas, $\mathrm{P} \& \mathrm{D}$, financiamento da produção, escala, marcas, distribuição), limitam a atuação dessas empresas às franjas desse mercado. A manutenção dessas franjas é também vantajosa às grandes empresas na medida em que constituem um mercado para a venda de seus produtos técnicos, além de servirem como barreiras a novos entrantes potenciais. Isto quer dizer que as características estruturais do mercado vão muito além do raio de ação do marco regulatório em vigor, cujo foco não é o de estimular a concorrência mas o de minimizar os riscos à saúde humana e ao meio ambiente.

Percebe-se aqui a capacidade das ações mesocorporativas dos grupos de interesse indicados de implementar estratégias voltadas a redefinir o foco e as prioridades das políticas públicas de forma a legitimar e legalizar seus interesses nos espaços de decisão do governo. Neste sentido, os referidos argumentos, em prol de uma legislação menos rigorosa, revela a defesa de interesses privados e de curto prazo no sentido da manutenção do status quo de uma parcela reduzida da sociedade. A necessidade, se houver, de um controle de preços ou de um controle de concentração excessiva do mercado, passaria na realidade por outras instâncias regulatórias ligadas à Secretaria de Direito Econômico, ou ainda de um maior incentivo às atividades de $\mathrm{P} \& \mathrm{D}$ neste campo de conhecimento, bem como na racionalização e na substituição 
do uso dessas substâncias. Ao mesmo tempo, a lógica de interesses privados de curto prazo conflita com uma prioridade de longo prazo e de interesse público maior, baseado na defesa da saúde humana e do meio ambiente. Tal interesse significa para o Brasil tanto uma condição de sustentabilidade ambiental quanto econômica, dado que o país é um grande exportador de commodities agrícolas para mercados cada vez mais exigentes nesses atributos. $\mathrm{E}$ é na combinação desses diferentes aspectos, apresentando ao mesmo tempo implicações ambientais e econômicas de curto e longo prazo, que o problema da regulamentação dos agrotóxicos deveria ser discutido.

\section{Referências}

ABIFINA. ASSOCIAÇÃO BRASILEIRA DAS INDÚSTRIAS DE QUÍMICA FINA. (2008)“Faturamento". URL: http://www.abifina.org.br/faturamento.asp. Acesso em: 10 de julho de 2008.

AENDA (2001).“Reduzindo a concorrência”. Editoriais. São Paulo. Seção Concorrência, n. 32. URL: http://www.aenda.com.br/informativo_o32.htm. Acesso em: 12 de janeiro de 2008 .

AENDA (2005). “O parto da equivalência”. Editoriais. São Paulo. Seção Genéricos, n. 79. URL: http://www.aenda.com.br/informativo_036.htm. Acesso: em 10 de janeiro de 2008.

AENDA (2007). “Os equivalentes”. São Paulo. Seção Especial Produtos Equivalentes. URL: http://www.aenda.com.br/new_equivalentes5.htm. Acesso em: 10 de fevereiro de 2008.

AENDA. ASSOCIAÇÃO BRASILEIRA DOS DEFENSIVOS GENÉRICOS.(2008a) "Alto custo para registrar defensivos genéricos". Editoriais. São Paulo. Seção Associadas, n. 04. URL: http://www.aenda.com.br/informativo_004.htm. Acesso em: 10 de janeiro de 2008.

AENDA (2008b). “Conceito”. Seção Concorrência. URL: http://www.Aenda.org.br/ new_concorrencia10.htm. Acesso em: 30 de agosto de 2008.

AGROW (2007). “Agrow's Top 20, Edition - DS 258”. URL: http://www.agrow.com/ reports/agrowtop_20_2007_chapter1.shtml Acesso em: 16 de julho de 2007.

ANDEF. ASSOCIAÇÃO NACIONAL DE DEFESA VEGETAL (2003). Comitês de trabalho. Seção Comitê de Trabalho sobre Legislação, São Paulo. URL: http:// www.andef.com.br/2003/asso05.asp. Acesso em: 17 de dezembro de 2007.

ANDEF (2005) "Posicionamento da indústria de defensivos agrícolas sobre a importação direta dos produtos pelo agricultor”. URL: http://www.andef.com.br/ defesa_agricola/ default.asp?cod=2. Acesso em: 10 de setembro de 2007.

BASF (2008). “Annual Report”. URL: http://www.corporate.basf.com/en/investor/ bestellcenter/?jahr=2001\&id=ccD7UCgfxbcp3dx Acesso em: 07 de agosto de 2008.

BAYER (2008). “Annual Report”. URL: http://www.bayer.com/en/Annual-Reports. aspx Acesso em: 07 de agosto de 2008. 
BELIK, W. (1992). Agroindústria processadora e política econômica. Campinas: Tese de Doutorado, Universidade Estadual de Campinas, Instituto de Economia.

BRASIL (1989). Lei 7802, de 11 de julho de 1989. Diário Oficial da União, República Federativa do Brasil, Brasília, 12/07/1989. URL: http://www.planalto.gov.br/ ccivil/leis/> Acesso em: 20 de junho de 2007.

BRASIL (2005). Agência Nacional de Vigilância Sanitária. "Nota técnica sobre livre comércio de agrotóxicos”. Brasília. URL: http://www.abrandh.org.br/index. php?arquivo=chegadeveneno. Acesso em: 12 de fevereiro de 2008.

BRASIL (2002). Decreto n. 4.074, de 04/01/2002. Diário Oficial da União, República Federativa do Brasil, Brasília, 05/01/2002. URL: http://www.planalto.gov.br/ ccivil/leis/. Acesso em: 03 de dezembro de 2007.

BRASIL (2006). Decreto n. 5.981, de o6 de dezembro de 2006. Diário Oficial da União, República Federativa do Brasil. Brasília, 07/12/2006. URL: http://www.planalto.gov.br/ccivil/leis/. Acesso em: 23 de agosto de 2007.

BRASIL (2007a). "Ministério do Desenvolvimento, Indústria e Comércio. Indústria Agroquímica.” In: Fórum de Competitividade. Diálogo para o Desenvolvimento. Brasília, 17p.

BRASIL (2007b). Nota técnica da ANVISA. Brasília: Agência Nacional de Vigilância Sanitária, 13p.

BULL, D. \& HATHAWAY, D. (1986). Pragas e venenos: agrotóxicos no Brasil e no terceiro mundo. Petrópolis: Vozes.

COELHO, N. C. (2001). “70 anos de política agrícola no Brasil (1931-2001)”. Revista de Política Agrícola 10 (Ed. Especial): 1-59.

CONSEA (2007). "Moção de repúdio à tentativa de flexibilização da legislação de agrotóxicos." In $3{ }^{\mathrm{a}}$. Conferência Nacional de Segurança Alimentar e Nutricional, Fortaleza.

DEFESA AGRÍCOLA (2006a). "Simplificação ou agilização ou agilização de registros? O que é melhor para o agronegócio brasileiro.” São Paulo 2(5). URL: http://www.Andef. com.br/defesa_agricola/default.asp?cod=5. Acesso em: 10 de setembro de 2007.

DEFESA AGRÍCOLA (2006b). "Posicionamento da Andef, do Sindag e da Abifina sobre o registro de produtos fitossanitários.” São Paulo, 2(3). URL: http://www. andef.com.br/defesa_agricola/default.asp?cod=3. Acesso em: 10 de setembro de 2007.

DEFESA AGRÍCOLA (2007). "Mercosul - a regulamentação e o comércio de produtos fitossanitários.” São Paulo, 2(4). URL: http://www.andef.com.br/defesa_agricola/ default.asp?cod=4. Acesso em: 10 de setembro de 2007.

FAO (1999). Manual on development and use of FAO specifications for plant protection products. Roma: FAO.

FRENKEL, J. \& SILVEIRA, J. M. (1996). “Tarifas, preços e a estrutura industrial dos insumos agrícolas: o caso dos defensivos". Textos para Discussão do IPEA. 412.

KAGEYAMA, A. (1990). “O novo padrão agrícola Brasileiro: do complexo rural aos complexos agroindustriais”. In: DELGADO, G. et al. (Org.) Agricultura e polí- 
ticas públicas. Brasília: IPEA, pp. 113-223.

IPEADATA (2008). “Brasília, 1940-2007.” URL: http://www.ipeadata.gov.br. Acesso em: 30 de novembro de 2008.

MARTINELLI, O. \& WAQUIL, P. (2002). "Tendências Recentes da Indústria de Defensivos Agrícolas no Brasil”. Análise Econômica 19(36): 123-42.

MARTINELLI, O. J. (2003). Agroquímicos: relatório setorial preliminar. Porto Alegre: UNESP/GEEIN/UNICAMP/DPCT, 46p.

MARTINS, P. R. (2000). Trajetórias tecnológicas e meio ambiente: a indústria de agroquímicos/transgênicos no Brasil. Campinas: Tese de Doutorado, Universidade Estadual de Campinas, Instituto de Filosofia e Ciências Humanas.

MCDOUGALL, P. (2008). “The global agrochemical and seed markets: industry prospects”. In Presentation at CPDA Annual Conference. San Francisco, 21st July.

NAIDIN, L. C. (1985). “Crescimento e competição na indústria de defensivos agrícolas no Brasil”. Rio de Janeiro: Dissertação de Mestrado, Universidade Federal Rural do Rio de Janeiro, Curso de Pós-Graduação em Desenvolvimento Agrícola.

NAIDIN, L. C. (1986). “Um mercado sobre reserva.” Ciência Hoje 4(22) : 53-56.

O ESTADO DE SÃO PAULO (2006). "Decreto facilita o registro de defensivos genéricos.” O Estado de São Paulo, 05 de dezembro de 2006. Seção B. URL: http:// www.andef. com.br/2003/noto6.asp. Acesso em: 20 de junho de 2007.

O ESTADO DE SÃO PAULO (2007). "Senadora revela Lobby em indicação da ANVISA.” O Estado de São Paulo, 25 de dezebmro de 2007. Seção Nacional. URL: http://www. estadao.com.br/nacional/not_nac100820,o.htm. Acesso em: 30 de dezembro de 2007.

POSSAS, M. (1985). Estruturas de mercado em oligopólio. São Paulo: Hucitec.

POSSAS, S. (2006). “Concorrência e inovação”. In: PELAEZ, V. \& SZMRECSÁNYI, T. (Orgs.) Economia da inovação tecnológica. São Paulo: Hucitec, pp. 13-41.

PELAEZ, V. (2008). "A firma face à regulação da tecnologia: a experiência da Monsanto”. In: SZMRECSÁNYI, T. \& DALLA COSTA, A. \& SBICCA, A. (orgs.) Empresas, empresários e desenvolvimento econômico no Brasil. São Paulo: Hucitec, pp. 281-303.

SAMUELS, W. (1989). "The legal-economic nexus". George Washington Law Review 57:1556-78.

SHORT, P. (1985). “Growing Agchem R \& D”. Chemical \& Engineering News 83(38): 19-22.

SILVA, L. R. (2000). “Similaridade”. Texto para discussão. Anvisa, Brasília.

SILVA, L. R. (2005). “Agrotóxicos”. Texto para discussão. Anvisa, Brasília.

SILVA, L. R. (2007). "Histórico da regulamentação dos agrotóxicos". Texto para discussão. Anvisa, Brasília.

SILVEIRA, J. M. (1993). Estudos sobre a competitividade industrial Brasileira: competitividade da indústria de defensivos agrícolas. Campinas: ECIB/UNICAMP/MCT, 9op. 
SINDAG (2007). "Sindicato Nacional da Indústria de Produtos para Defesa Agrícola. Histórico”. URL: http://www.sindag.org.br. Acesso em: 29 de agosto de 2007.

SINDAG (2008). "Estatísticas de Mercados do Sindicato Nacional da Indústria de Produtos Para Defesa Agrícola.” São Paulo, 1995-2007. URL: http://www. sindag.org.br. Acesso em: 15 de janeiro de 2008.

SYNGENTA (2008). “Annual Report” URL: http://www.syngenta.com/en/ investor\%5Frelations/financial_information.html Acesso em: 07 de agosto de 2008.

TERRA, F. \& PELAEZ, V. (2007). “A regulamentação da tecnologia e da concorrência”. In II Simpósio Nacional de Tecnologia e Sociedade. Curitiba, 5-8 de novembro.

TERRA, F. (2008). A Indústria de Agrotóxicos no Brasil. Curitiba: Dissertação de Mestrado, Universidade Federal do Paraná, Programa de Pós-Graduação em Desenvolvimento Econômico.

TOMITA, R. Y. (2005). "Legislação de agrotóxicos e sua contribuição para a proteção da qualidade do meio ambiente”. Biológico 67 (1/2): 1-10.

VELASCO, L. \& CAPANEMA, L. (2006). “O setor de agroquímicos”. BNDES Setorial 24: 69-96.

Recebido em: 18 de fevereiro de 2009.

Primeira resposta em: 7 de março de 2009.

Aceite em: 12 de março de 2009. 